\title{
Using Professional Leadership to Promote Multicultural Understanding and Social Justice
}

\author{
Patricia Arredondo \\ Arizona State University, United States of America
}

\begin{abstract}
Social justice icons, like Rosa Parks, Mahatma Ghandi, Martin Luther King, Jr. and César Chávez, Sknown for their tireless, courageous leadership initiating societal changes that have benefited many, lead the way for contemporary professional psychologists. These leaders opened pathways for inclusive principles and practices in education, employment, and political contexts. At the same time, professional leadership on behalf of multicultural and social justice issues in professional organisations and other contexts is known to be challenging. Biases and assumptions, micro-aggressions, and ignorance of experiences with interpersonal oppression are communicated daily. In multiculturally diverse global societies, social justice leadership is in great demand. Psychologists are encouraged to develop multicultural competencies in educational, research, and organisational practices and emulate the social justice icons.
\end{abstract}

\begin{abstract}
'We cannot seek achievement for ourselves and forget about progress and prosperity for our community ... Our ambitions must be broad enough to include the aspirations and needs of others, for their sakes and for our own' (www.Thinkexist.com).
\end{abstract}

As I thought about the topic for this article, I was immediately drawn to the words and examples of Latinos and non-Latinos alike who had the courage to give leadership in the midst of societal obstacles to social justice. César Chávez is most often recognised for his role as a civil rights activist primarily on behalf of migrant farm workers. Dolores Huerta was at the frontlines as well, taking risks to her personal well-being because of her beliefs in the rights of the oppressed migrant workers. Though not elected professional leaders, César Chávez and Dolores Huerta empowered themselves to be social justice advocates (del Castillo \& Garcia, 1995).

Like the Reverend Martin Luther King Jr., they believed in the human dignity of people and in the use of nonviolent means to challenge authority. The words of Dr King are another reminder of the necessity of professional leadership in the social justice domain. He stated, 'Injustice anywhere is a threat to justice everywhere'. It may be obvious in these first few sentence that my paradigm for professional leadership has been influenced by the examples of humanitarians.
The purpose of this article is to address the individual, group, and organisational responsibilities to use professional leadership roles in counselling and psychology to create multicultural understanding and social justice. In this treatise, I shall discuss the personal meaning of professional leadership, multicultural organisational development, exemplars to promote multicultural understanding and social justice practices in professional psychology, and how these exemplars and the inspiration of multicultural and social justice advocacy can be invoked to guide our work. I shall begin with a personal statement.

\section{An Odyssey in Professional Leadership}

Before I can begin to offer perspectives on the importance of professional leadership to promote multicultural understanding and social justice, it seems prudent to begin with a personal account. My own leadership journey within professional counselling and psychology is inspired by role models, their acts and words, and of course personal experiences that have reinforced my desire to be a leader. I hope that this discussion can provide a context for my opinions, admonitions, hopes, and recommendations to others who choose to step in to leadership roles.

I am of Mexican-American origin, US-born, second generation, and privileged because of my formal

Address for correspondence: Patricia Arredondo, Associate Vice Chancellor Academic Affairs, Educational Psychology Department, University of Wisconsin-Milwaukee, University of Wisconsin-Milwaukee, PO Box 413, 2200 E. Kenwood Blvd, Milwaukee, WI 53201-0413, United States of America. E-mail:empow@aol.com 
education. These are assets that have allowed me to create pathways in to new territories as a woman of colour. I am mestiza, the product of the European (Spanish) conquest of the indigenous people in Mexico. Being mestiza is also an identity with rich cultural roots and traditions in the pre-Colombian world. My heritage is affirmed in many ways and through the development of knowledge about this cultural history. The work of Manuel Ramirez III (1998) captures the essence of mestizo worldview that is also the basis for my professional leadership: the interdisciplinary focus, emphasis on collaboration and interdependence, the synthesis of values and interests for the greater good, being a change agent, appreciation for the historicalpolitical, identification of systems of oppression for the purpose of intervening, the fluidity and flexibility of culture, and the use of positions of power to empower.

Prior to embarking on my high school studies, I recall my mother's annual reminder about how few Mexican (students of Mexican origin) graduated from high school. This statement, supported by my own observations that there were no Latino teachers, elected officials, or other visible authorities or leaders in our community, fuelled my desire to step into leadership roles. Deficit thinking about Mexicans by others and at times by myself, led to what is called compensatory behaviour. Being twice as good as others who are perceived to have the power and control in a variety of settings has been discussed in the feminist women's literature (Baker Miller, 1976; Eisendrath \& Wiedemann, 1987) and in models of racial identity development (Sue \& Sue, 2003). I was conscious of my deliberateness and push to be yearbook editor, on the debate team, and president of the Future Teachers Club - no other Mexican American had done this (to my knowledge). I wanted to set the example and had to be impeccable in these visible settings.

A second motivator for stepping into leadership roles has been, and continues to be, that of giving voice to issues and concerns that have been unaddressed in the profession. I feel an obligation to speak up as an individual with a conscience about social justice issues, as an experienced professional who can hopefully encourage others, especially emerging professionals and students to do the same, and also as an elected leader. Unmistakably, legitimate power can provide a moral compass to issues of social justice and multiculturalism in counselling and psychology.

Though not often discussed, there is a tremendous amount of psychic energy that is exhausted when one tries to be a leader in unfamiliar territory, surrounded by others who represent the majority culture's social identities, (for example, white, male, heterosexual, able-bodied, attractive), and where personal pressures to achieve are relentless. As a pioneer of sorts in the professional leader arena of counselling and psychology, I have had experiences that have been stressful, invigorating, painful, heart-warming, disappointing, and 'growthful'. The image of a butterfly comes to mind. At times my heart fluttered as I succeeded in a new role and then there is the metaphor of the wounded bird whose wings weaken in flight.

Professional leadership on behalf of issues of multiculturalism and social justice is very challenging. Unchecked biases and assumptions, micro-aggressions, and ignorance of others about what it means to be oppressed are communicated on a daily basis. When people say that they have never experienced discrimination and that their grandparents were also immigrants, they are negating that for many of us, there is a part of our identity (e.g., conquest, heritage, colour) that cannot be changed. Although I may not be the direct target of discriminatory behaviour in the workplace, I am aware that others of Mexican heritage experience recurring incidents of disrespectful and abusive behaviour. As a professional leader, I have a responsibility to initiate actions that can change such practices. With my influence and leadership, I must engage these issues, not ignore them.

My personal odyssey in the world of professional leadership has also required continuous knowledge and competency-building. These are topics I write about and promote. In the subsequent sections, I will discuss some of the areas of competency that I consider essential to promote multicultural understanding and social justice through professional leadership. After all, leaders, like emperors, are also subject to not wearing clothes, except when the individual was Mother Teresa. Although I do not intend to compare my journey to hers, one of her sayings seems appropriate to summarise my ideas. She stated, 'We should learn how to give. But we should not regard giving as an obligation, but as a desire' (1996, p. 19).

\section{The Context for Multicultural Understanding The Academic Agenda}

In the professions of counselling and psychology, considerable time is spent addressing the value of research to inform education and training, practice, and societal issues. However, since these professions have their own respective histories, missions and cultural attributes are multidimensional with varied specialty areas and applications. Further, it is posited, that counselling and psychology, as international professions, are dynamic, not static. These professions continue to evolve, informed by external social, cultural, economic and political forces, human development and scientific discoveries. Inasmuch as these professions like others are culture-bound (e.g., values-based), leaders of the professional organisations have an obligation to provide leadership in the domains of multiculturalism and social justice, giving voice to principles, issues, and models that have been developed for the benefit of humankind 
(Arredondo \& Perez, 2003). For those who become involved with roles of governance, volunteerism, and other forms of professional leadership in our academic institutions, agencies, and other work contexts, it is incumbent upon us to address these issues.

\section{Defining the terms}

Multicultural understanding is based on premises of multicultural competency that lead to respectful relationships among individuals and groups. Multicultural understanding also presumes the ability to do role-taking, be empathic, suspend judgment and promote conciliatory relations in the midst of opposing forces. Articulation of competency-based principles and behaviour is documented in the Multicultural Counselling Competencies (Arredondo et al., 1996; Sue, Arredondo \& McDavis, 1992) developed by the Association of Multicultural Counselling and Development (AMCD) and endorsed by the parent organisation, American Counselling Association (ACA) and the Multicultural Guidelines on Education and Training, Research and Practice for Organizational Change (American Psychological Association, 2003).

Multicultural competency refers to the multidimensional capacity to know oneself as a cultural being, to be knowledgeable about the cultural worldview of others so that such awareness and knowledge will guide one's actions as a professional leader in multicultural contexts. (More discussion follows as multicultural competency relates to professional leadership.)

Professional leadership in this discussion refers to behaviour attributed to individuals who are elected, appointed, and or otherwise assume a role of leadership. In such roles, leaders must go beyond their ambitions and do so with ethical ambition (Bell, 2002). According to Bell, this also involves passion, courage and risk-taking, promoting relationships, being humble and being an 'activist for social justice' (Bell, 2002, p. 6).

Servant leadership as defined by Greenleaf (1977) posits that the 'servant-leader' prioritises serving rather than being a leader and that the individual's initiative is where servant leadership begins. Examples of servant leadership include contemporary champions of social justice and multicultural diversity such as César Chávez, Dolores Huerta, Martin Luther King, Jr., Nelson Mandela, and Mother Teresa.

Social justice refers to a philosophy and practices that promote a sense of fairness, justice, and advocacy on behalf of individuals who are cannot speak for themselves or who otherwise are oppressed for who they are. Vera and Speight (2003) state that psychologists (mental health professionals) must be at the forefront of activism, utilising the principles of collective decision making and community empowerment to act on behalf of those in society who have become disenfranchised, marginalised, and oppressed.

\section{Multicultural Competency — Underpinnings for Professional Leadership}

For more than 30 years, a growing number of counselling and psychology professionals have been advocating, through multiple venues, to bring a focus to the value and necessity of multicultural competence in education and training, research, and practice. Although the emphasis in early documents was on clinical practice (Sue, Arredondo, \& McDavis, 1992; Sue et al., 1982) this clinical focus continued to expand to education and training, research, and organisational change strategies. There was also a realisation that clinicians and clients are in a relationship and that this relationship takes place in a context affected by different internal and external societal forces. Thus, additional attention was given to clinician advocacy and systems change (Arredondo et al., 1996) in a document that operated through 119 Explanatory Statements, 31 multicultural competencies. One statement is, 'Culturally skilled counsellors can recognise and discuss examples in which racism or bias may actually be imbedded in an institutional system or in society' (Arredondo et al., 1996, p. 71) and take action.

The multicultural competency model is tripartite (Figure 1) with the domains described as: Counsellor Awareness of Cultural Attitudes, Beliefs and Biases, Counsellor Awareness of Client Worldview, and the Synergetic Application of Cultural Informed Interventions and Strategies. Within each domain are three areas of competencies: awareness, knowledge, and skill-building. Specific to the topic of leadership, specific competency statements might state: culturally competent professional leaders are aware of biases and assumptions held about others in the organisation; who is capable of being an organisational leader, and the constituencies the organisation serves. Some may think that women, people who are 'too young' (ageism), or individuals who speak with a foreign accent are not suitable for leadership assignments.

Professional leaders must also be: aware of their interpersonal style and how this may need to be adapted when communicating with individuals who are immigrants or from an underrepresented cultural or diversity group; aware of feelings of comfort and discomfort with different constituencies and why these feelings occur; knowledgeable about dimensions of personal identity (see Figure 2) that suggest that all people have intersecting social identities and the benefits we derive from these identities are based on historical and political access to power and privilege (or the lack thereof). (For example, immigration is a major life event catalysing numerous transitions, upsets, and opportunities. However, the effects of immigration will be variable for people based on their country of origin, educational achievement, and ethnic heritage. Persons of colour who are immigrants face more societal barriers in the US than white immigrants.) 
Professional leaders must also be: knowledgeable about culture-specific communication norms for particular constituencies (e.g., American Indian tribes such as Navajos and an Amish person), especially when there is regular involvement; capable of creating organisational change that will provide access to individuals and or groups that historically have been not included in the business activities of the organisation; willing to take positions on unpopular social issues such as antibilingual education and anti-immigrant movements. In particular, these affect Latinas/os (Santiago-Rivera, Arredondo, \& Gallardo-Cooper, 2003).

They must be willing to use the multicultural competencies to address institutional oppression (Arredondo, 1999), be aware of the limits of their cultural competency, and ask for consultation, particularly for culture-specific advice when needed.

Professional leaders must have a broad repertoire of competencies, particularly since the organisations they likely lead are diverse by nature. When I served as president of the National Latina/o Psychological Association, I always reminded members and others that: (a) the organisation was not limited to persons of Latina/o heritage; and (b) Latinos are a highly heterogeneous group and that this would be evident in our members who were from different religious backgrounds, countries of origin, sexual orientation and research interests.

Leaders of large, national organisations such as ACA and APA must be mindful of the broad constituency base they represent. As elected, volunteer leaders, counsellors, and psychologists, we speak for the profession, professionals and the constituencies we purport to represent. Accordingly, we must be willing and prepared to engage in difficult dialogues. According tobell hooks, 'Unfortunately, it is often easier to ignore, dismiss, reject, and even hurt one another rather than engage in constructive confrontation' (2000, p. viii). Promoting multicultural understanding and social justice requires engagement in disagreements and verbal conflicts that create dissonance. Professional leaders cannot shy away from these discussions.

\section{Exemplary Leaders for Multicultural Understanding}

My ideas about exemplary leaders became evident earlier in this article. As I reflect on exemplary figures that have impressed me, I notice how their words and deeds are consistent with the mestizo worldview. The Reverend Martin Luther King, Jr, bell hooks, Nelson Mandela and Mother Theresa espoused values that promote respect, fairness and justice for all people, power-sharing, compassion, love, faith, persistence, and idealism. Without faith, Nelson Mandela could not have led the demise of apartheid in South Africa. Without faith and perseverance, César Chávez and Dolores Huerta could not have brought the grape-growers to negotiate on behalf of the migrant workers. Without faith, and a dream for justice and equality, Martin Luther King Jr could not have led the Civil Rights movement in the US. When I reflect on the monumental changes these individuals provoked, I know that I can continue to learn and lead from their examples.

\section{Responsibilities for Professional Leaders}

Multicultural understanding is essential in all facets of life, including professional leadership. How leaders live their personal lives cannot be different from how we live our professional lives. I do not mean to suggest that we are flawless beings, but I do strongly recommend that we take inventory. In a society where diversity of social groups continues to evolve in highly visible and at times divisive ways, professional leaders must be clear on our beliefs about issues such as the rights of undocumented immigrants, same-sex marriage, gays in the military and English-only policies.

As a professional leader in a multiculturally complex society, I depend on the wisdom of elders, consultation with colleagues and friends, and reflection on past experiences in leadership and nonleadership roles. I know that my behaviour reflects on others therefore I want it to be exemplary. There is accountability as a professional leader to promote social justice and multicultural understanding. From a collectivistic, interdependent worldview, I believe that the accountability is first to those we serve. As a servant leader, I am servant first.

\section{Acknowledgment}

Dr Jesse R. Aros co-developed the original paper presented at the American Psychological Conference in Hawaii, and contributed to the substance of this article.

\section{References}

American Psychological Association (2003). Guidelines for multicultural education and training, research, practice, and organizational change for psychologists. American Psychologist, 58, 377-402.

Arredondo, P. (1999). Multicultural counselling competencies as tools to address oppression and racism. Journal of Counseling and Development, 77, 102-108.

Arredondo, P., \& Perez, P. (2003). Expanding multicultural competence through social justice

leadership. The Counseling Psychologist, 31, 282-289.

Arredondo, P., Toporek, R., Brown, S.P., Jones, J., Locke, D.C., Sanchez, J., \& Stadler, H.

(1996). Operationalization of the multicultural counseling competencies. Journal of

Multicultural Counseling and Development, 24, 42-78.

Bell, D. (2002). Ethical ambition. New York: Bloomsbury.

del Castillo, R.G., \& Garcia, R.A. (1995). César Chávez: A triumph of spirit. Norman, OK: University of Oklahoma Press. 
Dreher, D. (1996). The tao of personal leadership. New York: Harper Business.

González-Balado, J.L. (1996). Mother Teresa-In my own words. New York: Gramercy Books.

Greenleaf, R.K. (1997). Servant leadership. New York: Paulist Press.

hooks, b. (2000). Feminist theory: From margin to centre (2nd ed.). Cambridge, MA: South End Press.

Miller, J.B. (1977). Toward a new psychology of women. Boston: Beacon Press.

Ramirez III, M. (1998). Multicultural/multiracial psychology. Northvale, NJ: Jason Aronson, Inc.

Sue, D.W., Arredondo, P., \& McDavis, R.J. (1992). Multicultural competencies and standards: A call to the profession. Journal of Counseling and Development, 70, 477-486.
Sue, D.W., Bernier, J., Durran, M., Feinberg, L., Pedersen, P., Smith, E., \& Vasquez-Nuttall, E. (1982). Position paper: Multicultural counselling competencies. The Counselling Psychologist, 10, 45-52.

Sue, D.W., \& Sue, D. (2003). Counseling the culturally diverse (4th ed.). New York: John Wiley \& Sons, Inc.

Thinkexist.com (2006). Retrieved from http://en.thinkexist. com/quotes/Cesar_Chavez/

Vera, E.M., \& Speight S.L. (2003). Multicultural competence, social justice, and counselling psychology: Expanding our roles. The Counseling Psychologist, 31, 253-272.

Young-Eisendrath, P., \& Wiedemann, F. (1987). Female authority. New York: The Guilford Press. 